\title{
Computer Graphics Applied to Anatomy: A Study of two Bio-CAD Modeling Methods on Finite Element Analysis of Human Edentulous Hemi-Mandible
}

\author{
Computación Gráfica Aplicada a la Anatomía: Un Estudio de Dos Métodos de Modelización \\ Bio-CAD sobre el Análisis de Elementos Finitos de Hemimandíbulas edéntulas humanas
}

\begin{abstract}
Ana Cláudia Rossi*; Alexandre Rodrigues Freire*; Paulo Roberto Botacin**; Paulo Henrique Ferreira Caria* \& Felippe Bevilacqua Prado*
\end{abstract}

ROSSI, A. C.; FREIRE, A. R.; BOTACIN, P. R.; CARIA, P. H. F. \& PRADO, F. B. Computer graphics applied to Anatomy: a study of two Bio-CAD modeling methods on finite element analysis of human edentulous hemi-mandible. Int. J. Morphol., 32(3):803-811, 2014.

SUMMARY: Modeling is a step to perform a finite element analysis. Different methods of model construction are reported in literature, as the Bio-CAD modeling. The purpose of this study was to perform a model evaluation and application using two methods of Bio-CAD modeling from human edentulous hemi-mandible on the finite element analysis. From CT scans of dried human skull was reconstructed a stereolithographic model. Two methods of modeling were performed: STL conversion approach (Model 1) associated to STL simplification and reverse engineering approach (Model 2). For finite element analysis was used the action of lateral pterygoid muscle as loading condition to assess total displacement (D), equivalent von-Mises stress (VM) and maximum principal stress (MP). Two models presented differences on the geometry regarding surface number (1834 (model 1); 282 (model 2)). Were observed differences in finite element mesh regarding element number (30428 nodes/16683 elements (model 1); 15801 nodes/8410 elements (model 2). D, VM and MP stress areas presented similar distribution in two models. The values were different regarding maximum and minimum values of $\mathrm{D}$ (ranging 0-0.511 mm (model 1) and 0-0.544 mm (model 2), VM stress (6.36E-04-11.4 MPa (model 1) and 2.15E-04-14.7 $\mathrm{MPa}$ (model 2) and MP stress (-1.43-9.14 MPa (model 1) and -1.2-11.6 MPa (model 2). From two methods of Bio-CAD modeling, the reverse engineering presented better anatomical representation compared to the STL conversion approach. The models presented differences in the finite element mesh, total displacement and stress distribution.

KEY WORDS: Computational modeling; Mandible; Finite element analysis; Biomechanics.

\section{INTRODUCTION}

The construction of the geometry is one of the steps for finite element analysis (FEA), where is commonly performed in a CAD program (Sun et al., 2005; Panagiotopoulou, 2009). For construction of biological models, techniques for imaging acquisition are fundamental. Different imaging references can be used for the anatomy reproduction based on anatomical landmarks (Panagiotopoulou). These references can be obtained from pictures of Anatomy books (Rudolph et al., 2001), digital radiography (Kondo \& Wakabayashi, 2009; Hasegawa et al., 2010), CT scans (Cattaneo et al., 2003; Sun et al.; Motoyoshi et al., 2009; Poiate et al., 2008, 2009; Strait et al., 2010) and MCT scans (Cattaneo et al., 2008; Boryor et al., 2009; Panagiotopoulou et al., 2011).
In $\mathrm{CT}$ or $\mu \mathrm{CT}$ scans, the anatomical structures can be segmented by "thresholding" due to differences densities expressed in Hounsfield units (HU) (Sun et al.). This process can be performed in public programs as InVesalius (Center for Technology and Information "Renato Archer", Brazil) (Silva et al., 2008; Pellizer et al., 2012, 2013) or commercial programs as Mimics (Materialise ${ }^{\circledR}$, Belgium) (Sun et al.; Poiate et al.; Szücs et al., 2010; Bujtár et al., 2010; Dong-Xu et al., 2011). From the segmentation, a 3D voxel model can be reconstructed, which is characterized by a point data form and the points are triangulated to form a faceted model (Sun et al., 2005). These models can be converted and exported as stereolithographic format (STL) featuring a model with triangulate mesh surface (Cattaneo et al., 2003; Kelley et al., 2007; Boryor et al.).

\footnotetext{
* Department of Morphology, Anatomy area, Piracicaba Dental School, State University of Campinas, Piracicaba, Sao Paulo, Brazil.

** Department of Basic Sciences, Anatomy area, Faculty of Dentistry of Araçatuba, Paulista State University, Araçatuba, Sao Paulo, Brazil.
} 
In FEA, STL models can be used as reference for modeling through the Bio-CAD method - biological structures modeled in CAD programs (Sun et al.). This method allows the construction of 3D models with high quality of anatomy geometry representation (Sun et al.) and importable for FEA programs (Sun et al.; Strait et al.). However, different methods of Bio-CAD modeling used in computational simulations can be found in the literature. These methods involve the "reverse engineering approach" and "STL converting approach" (Sun et al.).

The reverse engineering approach uses the 3D model exported from segmentation, as STL model, through importation into CAD programs (Sun et al.). In this process, the freeform surfaces of NURBS (Non-Uniform Rational B-Spline) patches are used to fit across the outer shape of the model. This method presents a CAD model with high quality in aesthetic, stable in configuration, and less error in data transfer formats, particularly for an integrated $\mathrm{CAD}$ and FEA application (Sun et al.).

In STL converting approach, the triangulate mesh surfaces can be automatically converted to NURBS surfaces, whose process results in surfaces featured by a triangular form (Sun et al.). Although this process can be fast for modeling of simple geometry structures (e.g. long bones), the STL models of complex craniofacial structures presents an excessive number of triangles, becoming complex for FEA programs and requiring high computational capacity (Cattaneo et al., 2003; Boryor et al.). Thus, the STL model simplification is an alternative to reduce these requirements (Cattaneo et al., 2003; Boryor et al.).

In order to reduce the complex configuration of the STL models, mathematical methods were developed, as the algorithm named "quadratic edge collapse decimation" (or quadratic-based surface simplification), that has the capacity for construction of low number of triangles from a high number of triangles by edge collapse (Heckbert \& Garland, 1999). Therefore, the triangle reduction has been applied for reduction of triangles number of complex craniofacial STL models (Cattaneo et al., 2003; Boryor et al.).

While reducing the number of triangles is an alternative to simplify STL models with heavy configurations, this process may result in changes in the morphology of these models (Boryor et al.). Changes in the morphology implies in incorrect results from computational analyses due to relation form and function (Panagiotopoulou).

There are publications the STL converting approach was used (Cattaneo et al., 2003, 2008; Nakajima et al., 2007;
Boryor $e t a l$.) and reverse engineering approach (Poiate $e t$ al., 2008, 2009; Motoyoshi et al.; Strait et al., 2009, 2010; Pelizzer et al., 2012) for modeling of the craniofacial structures. Thus, the aim of this study was to perform a finite element analysis applying these two Bio-CAD methods for construction of 3D model of human edentulous mandible.

\section{MATERIAL AND METHOD}

Imaging acquisition. CT scans of a human dried edentulous mandible with $0.4 \mathrm{~mm}$ thickness (i-CAT® Cone Beam 3-D Imaging System, Imaging Sciences Internation, USA) were used for 3D reconstruction using the public software InVesalius 3.0b (Center for Technology and Information "Renato Archer", Campinas, Brazil). The segmentation of anatomical structures was performed by thresholding. The structures considered for this study was the compact and cancellous bone. The $3 \mathrm{D}$ reconstruction was exported as binary STL format.

\section{Bio-CAD modeling}

STL conversion approach (model 1). From the CT image segmentation resulted in two STL models referred to the compact and cancellous bone. These STLs was imported into the MeshLab software v1.3.0 (Visual Computing Lab., ISTI - CNR, Italy) for polygonal mesh simplification. The original STLs were constituted by a triangulate mesh with total 84044 triangles. For the STL simplification we used the triangle reduction through the quadratic edge collapse decimation. The number of triangles was reduced to 1834 after algorithm application.

The simplified STLs were imported into the Rhinoceros 3D 4.0 software (NURBS Modeling for Windows, McNeel \& Associates, USA). In this software the STL meshes were automatically converted to NURBS surfaces and exported as solid STEP format (.step) (Fig. 1).

Reverse engineering approach (model 2). The original STLs were imported into Rhinoceros 3D 4.0 software and were worked in two different layers. In this process, curves and polylines were drawn manually following the anatomical landmarks. After drawn, were checked all intersections between the curves and a polysurface were created through the network of the curves (Fig. 2). Then, two solids were created and were exported as STEP format.

Finite Element Analysis. This study used the lateral pterygoid muscle contraction to evaluate its effects on two models using FEA. This muscular action results in the medial 

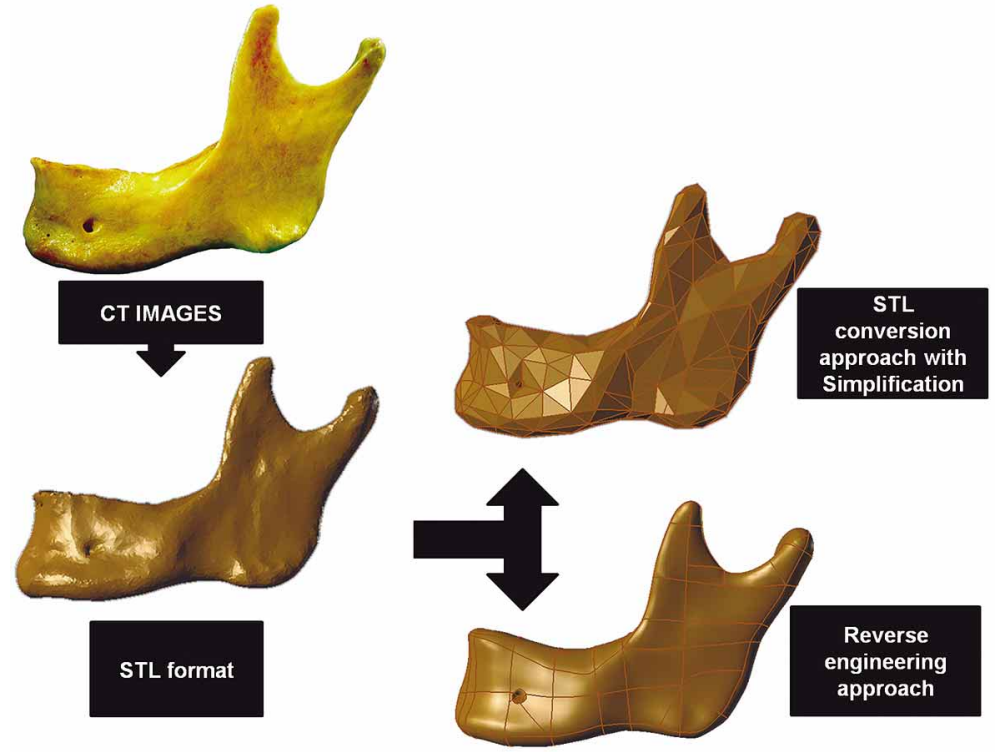

Fig. 1. Two Bio-CAD methods steps showing the STL model and geometry acquisition by STL conversion approach with simplification and reverse engineering approach.

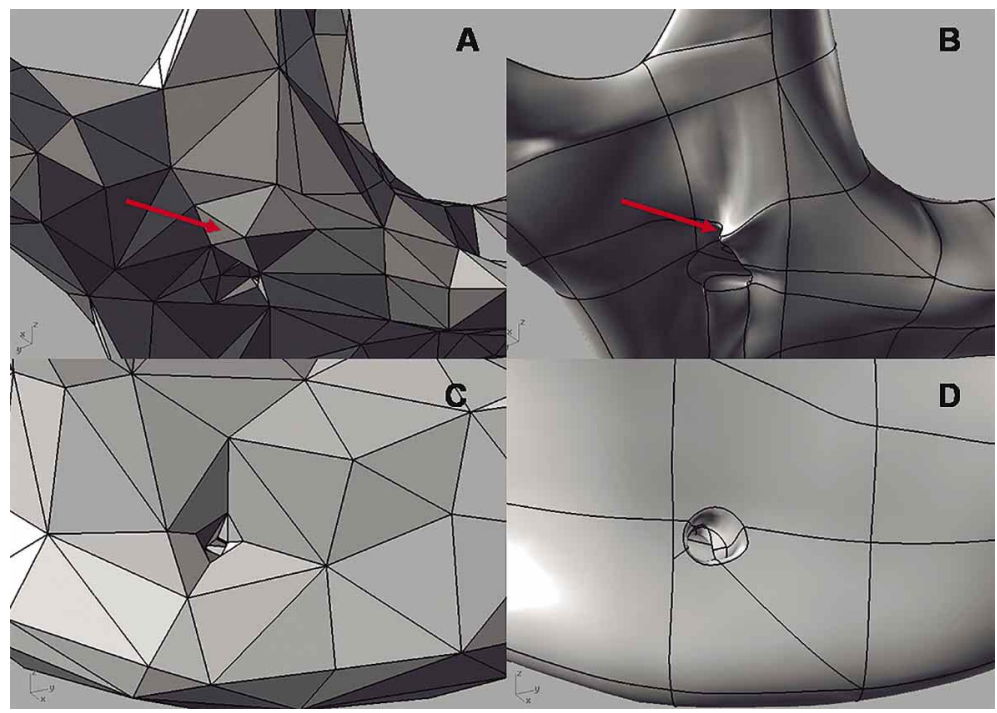

Fig. 2. Comparison of the two models regarding anatomical preservation. Two structures are demonstrated: the lingula in STL conversion approach after simplification was lost (A) and preserved in reverse engineering approach (B); the mental foramen have a polygonal aspect in STL conversion approach (C) and similar to the real structure in reverse engineering approach (D).

displacement of the mandible ramus. The consequence is the occurrence of stresses at the ramus and symphysis region.

Table I. Mechanical properties of anatomical structures.

\begin{tabular}{lcc}
\hline Anatomical structures & Young's Modulus* & Poisson Ratio \\
\hline Cortical bone & 10700 & 0.3 \\
Cancellous bone & 910 & 0.3 \\
\hline
\end{tabular}

*Megapascal (MPa).
The models 1 and 2 were imported into ANSYS v12 software (ANSYS, Inc. Canonsburg, PA, USA) for finite element meshing (Fig. 3) and analysis. The meshing process was performed automatically on both models. The mechanical properties (Young's modulus and Poisson's ratio) were used to simulate the compact and cancellous bone (Table I), whose values were obtained in the literature (Ona \& Wakabayashi, 2006). For the boundary conditions the symmetry condition on the symphysis region was applied and the bone was constrained in the three axes ( $\mathrm{x}, \mathrm{y}$ and $\mathrm{z}$ ), simulating a static condition.

A force load was applied on the surface of pterygoid fovea simulating the action of maximum contraction of the lateral pterygoid muscle. A resultant force with $74.75 \mathrm{~N}$ magnitude was used(Celebi et al., 2011) (Fig. 4).

The results were assessed by the analysis of total displacement (D), Equivalent von-Mises stress (VM) and Maximum principal stress (MP) (Figs. 5, 6 and 7).

\section{RESULTS}

Geometry. The geometry of both models presented small differences in the reproduction of the mandibular morphology. Due to the STL simplification, the model 1 presented loss of structures on the superficial anatomy, as the masseteric and pterygoid tuberosity and the lingula (Fig. 2). Moreover, the simplification resulted in a model with structures of high polygonal aspect on its surface, where it was observed at the mandibular incisure and the mental foramen (Fig. 2). The coronoid and condylar process, oblique line, mental protuberance and mental tubercle were better preserved featured by low polygonal aspect.

The model 2 presented high quality in the reproduction of the mandibular morphology. Different to the model 1, the structures as the masseteric and pterygoid tuberosity, lingula and mental foramen were preserved (Fig. 2). The reverse engineering approach resulted in a model with smoothed surface, whose characteristic is present in the real structure (Fig. 1), improving the superficial anatomy preservation. 

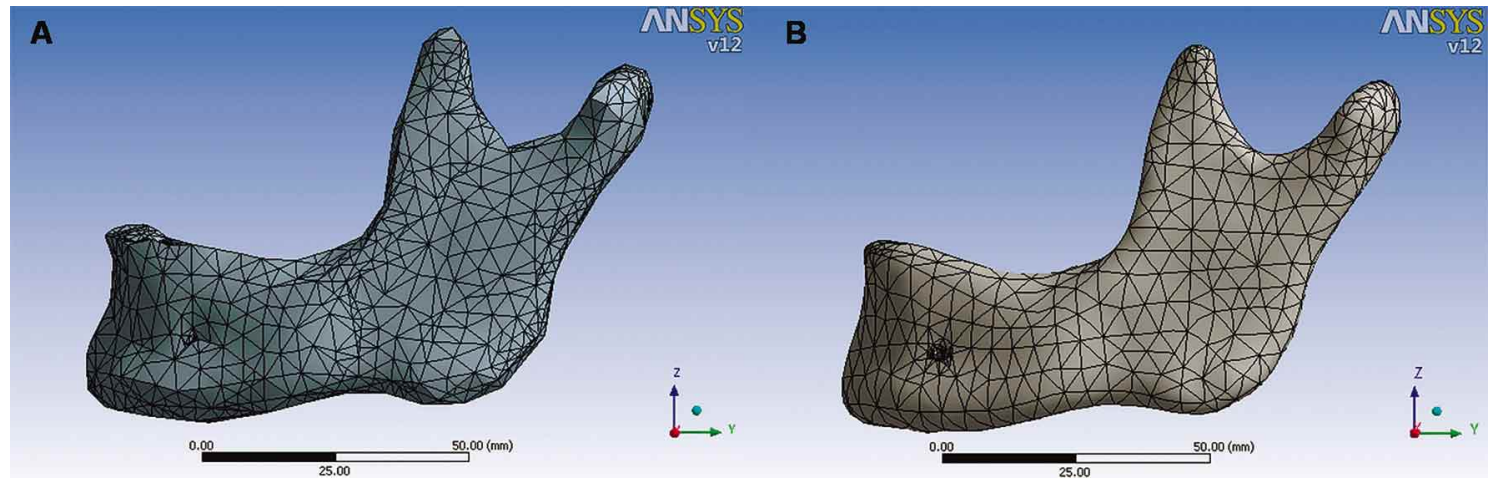

Fig. 3. Finite element mesh of the model 1 (A) and model 2 (B).

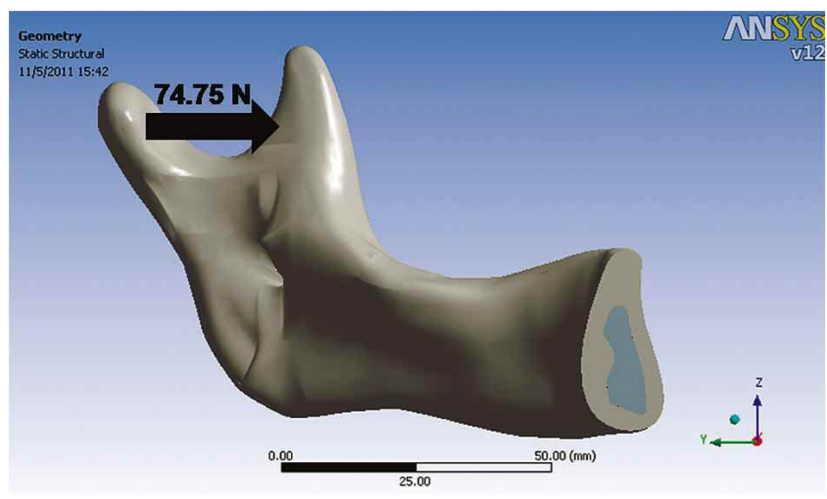

Fig. 4. Loading condition showing the direction and magnitude of the lateral pterygoid muscle action.

The two models presented differences in its total area and number of surfaces (Table II). Regarding the area, there was no significant difference while between their numbers of surfaces there was high difference.

Finite element mesh. In the two models, the finite element mesh was generated automatically. No problems on the geometry occurred during this process on both models. Regarding mesh configuration, the model 1 presented greater number of regions with irregularities compared to the model 2 (Fig. 3). The model 1 presented a mesh with 30428 nodes and 16683 tetrahedral elements (Table II). Model 2 presented 15801 nodes and 8410 tetrahedral elements (Table II).

Total displacement and stress distribution. The models presented the same regions where occurred displacement. The maximum D occurred at the articular surface of the mandibular condyle and the minimum D occurred at the symphysis on both models (Fig. 5). However, the values of maximum and minimum D were different (Table III).

Regarding the VM stress, models did not present significant differences on the stress distribution. The areas of stress concentration were similar on the both models (Fig. $6)$. The maximum VM stress concentrated at the mandibular ramus, clear to the mandibular neck and the minimum occurred at the apex of the coronoid process (Fig. 6). The difference was observed in the maximum and minimum values (Table III).

Table II. Comparison of two models regarding total area, number of surfaces, number of elements and number of nodes.

\begin{tabular}{llccc}
\hline & Total Area* & $\begin{array}{c}\text { Total number of } \\
\text { surfaces }\end{array}$ & $\begin{array}{c}\text { Total number } \\
\text { of elements }\end{array}$ & $\begin{array}{c}\text { Total number of } \\
\text { nodes }\end{array}$ \\
\hline Model 1 & $22991.70 \pm 1 \mathrm{E}-05$ & 1834 & 16683 & 30428 \\
Model 2 & $22375.34 \pm 1.9 \mathrm{E}-04$ & 282 & 8410 & 15801 \\
\hline
\end{tabular}

*Square millimeters $\left(\mathrm{mm}^{2}\right)$.

Table III. Total displacement and stress values from finite element analysis of two models.

\begin{tabular}{lcccccc}
\hline & \multicolumn{2}{c}{ Total Displacement* } & \multicolumn{2}{c}{ Equivalent von-Mises stress** } & \multicolumn{2}{c}{ Maximum Principal stress** } \\
\cline { 2 - 7 } & Minimum & Maximum & Minimum & Maximum & Minimum & Maximum \\
\hline Model 1 & 0 & 0.511 & $6.36 \mathrm{E}-04$ & 11.4 & -1.43 & 9.14 \\
Model 2 & 0 & 0.544 & $2.15 \mathrm{E}-04$ & 14.7 & -1.2 & 11.6 \\
\hline
\end{tabular}

*Millimeters (mm). **Megapascal (MPa). 


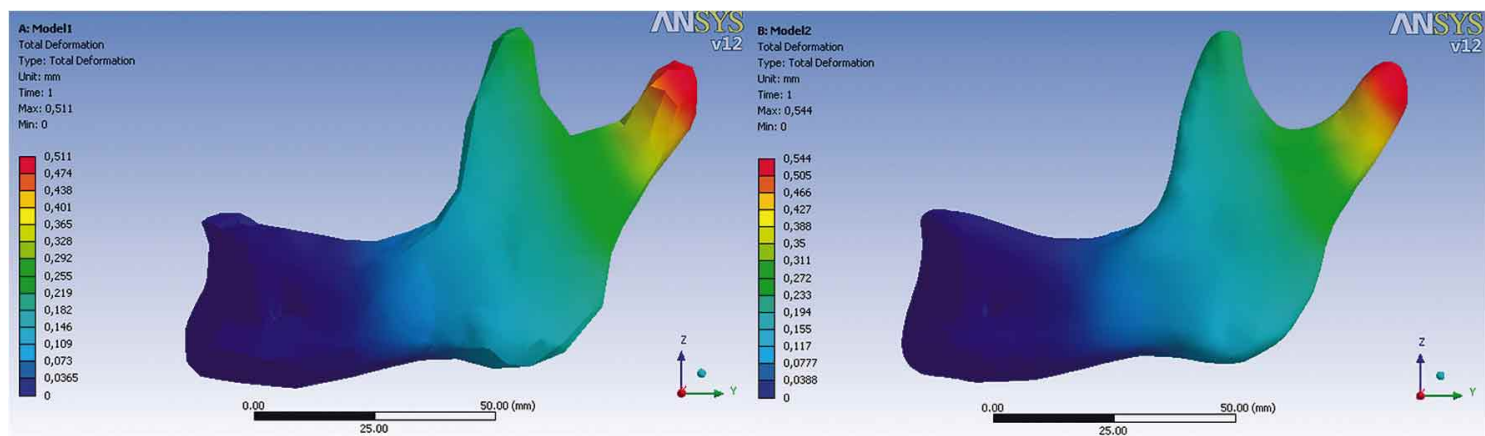

Fig. 5. Lateral view of the models 1 and 2 showing total displacement. Red and blue colors indicate the maximum and minimum values, respectively. Values in millimeters (mm).

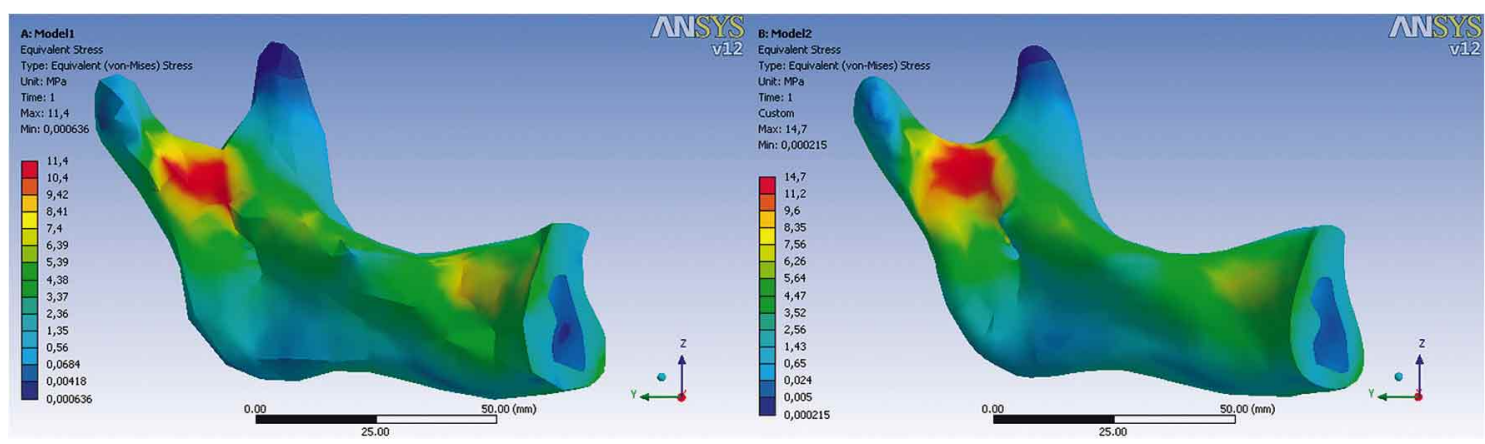

Fig. 6. Medial view of the models 1 and 2 showing equivalent von-Mises stress. Red and blue colors indicate the maximum and minimum values, respectively. Values in MPa.

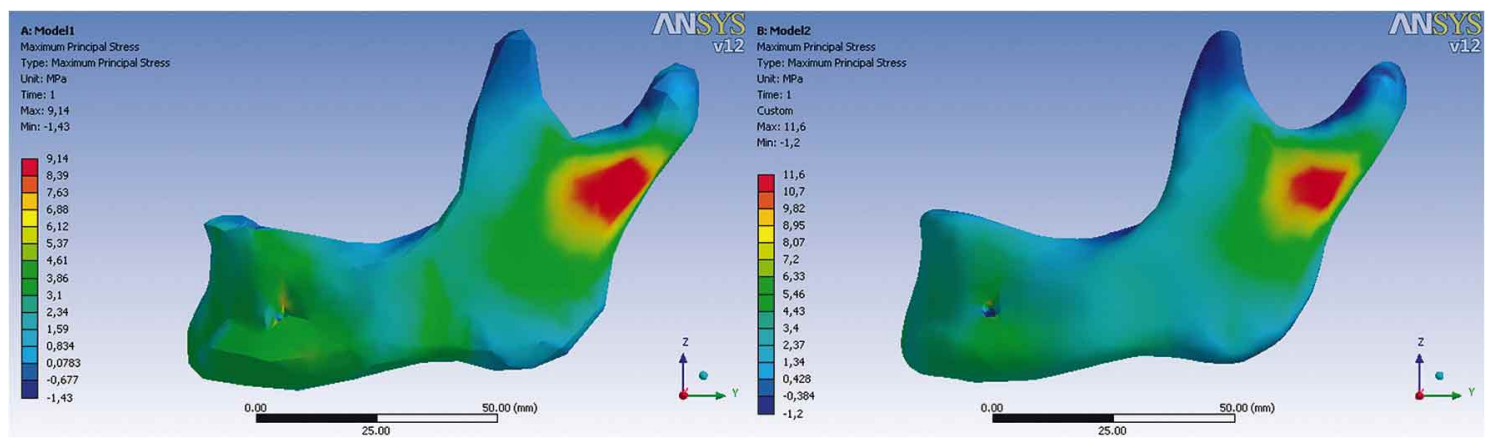

Fig. 7. Lateral view of the models 1 and 2 showing maximum principal stress. Red and blue colors indicate the maximum and minimum values, respectively. Values in MPa.

The MP stress showed no significant differences on the stress distribution. Tensile stress areas (positive values) occurred at the pterygoid fovea, mandibular ramus and mandibular body on the lateral surface and compressive stress (negative values) at the medial surface in both models (Fig. 7). The maximum concentration of tensile stress occurred at the mandibular ramus on the lateral surface, clear to the mandibular neck (Fig. 7). The maximum concentration of compressive stress occurred at the symphysis on the medial surface (Fig. 7). The difference was observed in the maximum and minimum values of MP stress (Table III).

\section{DISCUSSION}

CT images have been essential for the evolutionary process of image interpretation associated to the modern techniques of segmentation. This association is currently used in biomedical engineering for disease diagnosis (Huang et al., 2010; Saha et al., 2011) and rapid prototyping (Sun et al.; Kelley et al.; Benazzi et al., 2011) or research in functional morphology associated to biomechanics through computational simulations (Panagiotopoulou; Chalk et al., 
2011; Strait et al., 2009, 2010). These applications require high quality of the computational models. The quality is related to computational and mathematical methods of modeling, which results in configuration improvement of virtual models (Benazzi et al.). However, when these computer methods are applied to the biological models, the correct morphological characteristics must be carefully worked, as these structures have a direct relation between form and function (Panagiotopoulou). Thus, methods of modeling that affects significantly the real structural morphology can results in incorrect computational simulations (Prado et al., 2013; Freire et al., 2014).

The details for anatomical reproduction can be related to the CT slice thickness. Studies constructed virtual models from a single tooth to full skull bones using thicker CT slices (ranging 2-30 mm) (von Ehler et al., 1975; Tanne et al., 1993; Is , eri et al., 1998), which resulted an adaptive model for FEA, but the preservation in anatomy details were low. On the other hand, studies used thin CT slices $(0.1-0.5$ $\mathrm{mm}$ ) for modeling of small scale models, as segments of maxilla with a single tooth (Poiate et al., 2009) and large scale models, as the skull of human and non-human primates (Strait et al., 2009, 2010; Chalk et al.), demonstrated high anatomy preservation. This present study used STL model of edentulous mandible using a $0.4 \mathrm{~mm}$ CT slice thickness, and the high anatomical preservation in original STL was observed (Fig. 1). Thus, it is evident that thinner CT slices results in high quality of anatomical reproduction.

For the modeling applied to microscopic structures, the $\mu \mathrm{CT}$ is necessary (Panagiotopoulou et al.). According demonstrated by the model constructed by Boryor et al., it was possible to preserve the bone trabeculae and the characterization of periodontal ligament, whose tissue presents irregularities due to extensions of its collagen fibers invading the alveolar bone in a model of mandible segment at the canine level. The modeling of these structures is possible due to the $\mu \mathrm{CT}$ slice thickness $(13-50 \mu \mathrm{m})$ (Cattaneo et al., 2008; Boryor et al.; Dong-Xu et al.).

The CT slice thickness used in this study favored the preservation of superficial anatomy on the original STL model and was possible to maintain the presence of anatomical landmarks on the mandible surface (e.g. the pterygoid and masseteric tuberosity) using the reverse engineering. However, in the model 1 there was a loss of these characteristics. These losses are related to the simplification by triangle reduction. In the model used by Cattaneo et al. (2003), the simplification was significant, with reduction of $92.28 \%$ from total triangle number $(25768$ was reduced to 1989) in a system composed by maxillary molars and parts of the maxillary and zygomatic bone. In this present study, the reduction was $97.8 \%$ (84044 was reduced to 1834). The amount of triangles was reduced until the maximum anatomical preservation. However, there are no reports in the literature of standard protocol for the use of this modeling method. According to Boryor et al., the simplification is performed adaptively to the model.

Regardless the model size, the anatomical preservation is important to achieve model validation (Panagiotopoulou, 2009). In the real tooth structure studied by Nakajima et al., was observed an enamel defect, whose characteristic was preserved on the virtual model in order to maintain the model validity. In this present study, the mandibular canal was preserved, even with the STL model simplification. This structure was not modeled in previous studies (Gomes de Oliveira et al., 2006; Ichim et al., 2007; Lovaldi et al., 2009; Wang et al., 2010; Takahashi et al., 2010).

Similar to this study, other analyses involved models characterized by different solids for each anatomical structure. In the literature can be found as solids formed by STL converting approach (Nakajima et al.; Cattaneo et al., 2003, 2008; Provatidis et al., 2008) as by reverse engineering approach (Ona \& Wakabayashi; Ichim et al.; Motoyoshi et al.; Poiate et al., 2008, 2009). For the two methods, the need to perform this process is due to different morphological characteristics and mechanical properties (Provatidis et al.). Through different solids can apply the mechanical properties individually in the FEA programs. On the other hand, there are studies with application of the mechanical properties based on segmentation process (Sun et al.; Szücs et al.; Bujtár et al.). For each region defined by radio densities (expressed in $\mathrm{HU}$ ), it was possible calculate the mechanical properties (Sun et al.).

The differences related to finite element mesh were observed. Regarding the element number, the amount was greater in the model 1 (Table III). Another factor was the irregularity on the mesh distribution, was also greater in model 1 (Fig. 3). The differences in number and mesh distribution can have occurred by major amount of surfaces and differences in the internal angles of the triangles, respectively. Thus, mesh control may be needed for quality improvement. Even with these characteristics, the mesh of model 1 did not cause problems during the solve processing.

The FEA performed in this present study aimed to demonstrate a possible similarity in the results using these two methods of geometry modeling. The results in postprocessing presented minimal difference regarding the total displacement (Fig. 4) and stress analyses (Figs. 5 and 6). 
The distribution demonstrated by color scale was similar in two models, being that the difference occurred in the maximum and minimum values of D, VM and MP stresses (Table III). The mechanical behavior in both models occurred according theoretical definitions on the action of lateral pterygoid muscle (medial displacement of mandible ramus). The differences in values could have occurred due to the differences on the finite element mesh, resulting from differences in the geometry.

\section{CONCLUSIONS}

In general, two methods were available for FEA, even the results showed minimal differences in total displacement and stress analyses.
Two methods used in this study resulted in virtual models with quality in anatomical representation. However, the most reliable anatomical reproduction in the feature transfer from original STL occurred in the reverse engineering. Modeling using STL conversion approach associated to STL simplification and reverse engineering approach is an effective alternative for low computational capacity in FEA. However, the time-consuming for modeling was much lower in STL conversion approach associated to triangle reduction application. The application of triangle reduction must be performed carefully to avoid loss of anatomical structures characterization. Thus, when the computational capacity requirement is considered, time-consuming and anatomical preservation in virtual model of human mandible, the reverse engineering approach is the most recommended.

ROSSI, A. C.; FREIRE, A. R.; BOTACIN, P. R.; CARIA, P. H. F. \& PRADO, F. B. Computación gráfica aplicada a la anatomía: un estudio de dos métodos de modelización Bio-CAD sobre el análisis de elementos finitos de hemimandíbulas edéntulas humanas. Int. J. Morphol., 32(3):803-811, 2014.

RESUMEN: El modelado es un paso para llevar a cabo un análisis de elementos finitos. Entre los diferentes métodos de construcción del modelo que se presentan en la literatura, está el modelado Bio-CAD. El propósito de este estudio fue realizar una evaluación del modelo y aplicación utilizando dos métodos de modelado de Bio-CAD desde la hemimandíbula humana edéntula en el análisis de elementos finitos. Desde tomografías computarizadas de cráneos humanos secos, fue reconstruido un modelo de estereolitografía. Se realizaron dos métodos de modelización: enfoque conversión STL (Modelo 1) asociado a simplificación STL y enfoque de ingeniería inversa (Modelo 2). Para el análisis de elementos finitos se utilizó la acción del músculo pterigoideo lateral como condición de carga para evaluar desplazamiento total (D), lo que equivale tensión de von Mises (VM) y la tensión principal máxima (MP). Los dos modelos presentan diferencias en la geometría de la superficie en relación con el número (1834 (modelo 1), 282 (modelo 2)). Se observaron diferencias en la malla de elementos finitos con respecto a número de elemento (30428 nodos/16683 elementos (modelo 1) y 15.801 nodos/8410 elementos (modelo 2)). La D, VM y áreas de tensión MP presentan distribución similar en ambos modelos. Los valores fueron diferentes respecto a los valores máximo y mínimo de $\mathrm{D}$ (desde 0 hasta $0,511 \mathrm{~mm}$ (modelo 1 ) y 0 a 0,544 mm (modelo 2), tensión VM (6,36E-04 - 11,4 MPa (modelo 1) y 2,15e-04 - 14,7 MPa (modelo 2) y tensiones MP(-1,43 a 9,14 MPa (modelo 1) y -1,2 a 11,6 MPa (modelo 2)) a partir de dos métodos de modelado de Bio-CAD. La ingeniería inversa presenta una mejor representación anatómica en comparación con el enfoque de conversión STL. Los modelos presentan diferencias en la malla de elementos finitos, el desplazamiento total y la distribución de la tensión.

PALABRAS CLAVE: Modelización computacional; Análisis de elementos finitos; Mandíbula; Biomecánica.

\section{REFERENCES}

Benazzi, S.; Fiorenza, L.; Kozakowski, S. \& Kullmer, O. Comparing 3D virtual methods for hemimandibular body reconstruction. Anat. Rec. (Hoboken), 294(7):1116-25, 2011.

Boryor, A.; Hohmann, A.; Geiger, M.; Wolfram, U.; Sander, C. \& Sander, F.G. A downloadable meshed human canine tooth model with PDL and bone for finite element simulations. Dent. Mater., 25(9):e57-62, 2009.

Bujtár, P.; Sándor, G. K.; Bojtos, A.; Szucs, A. \& Barabás, J. Finite element analysis of the human mandible at 3 different stages of life. Oral Surg. Oral Med. Oral Pathol. Oral Radiol. Endod., 110(3):301-9, 2010.
Cattaneo, P. M.; Dalstra, M. \& Melsen, B. Moment-to-force ratio, center of rotation, and force level: a finite element study predicting their interdependency for simulated orthodontic loading regimens. Am. J. Orthod. Dentofacial Orthop., 133(5):681-9, 2008.

Cattaneo, P. M.; Dalstra, M. \& Melsen, B. The transfer of occlusal forces through the maxillary molars: a finite element study. Am. J. Orthod. Dentofacial Orthop., 123(4):367-73, 2003.

Celebi, N.; Rohner, E. C.; Gateno, J.; Noble, P. C.; Ismaily, S. K.; Teichgraeber, J. F. \& Xia, J. J. Development of a mandibular motion simulator for total joint replacement. J. Oral Maxillofac. 
Surg., 69(1):66-79, 2010.

Chalk, J.; Richmond, B. G.; Ross, C.F.; Strait, D. S.; Wright, B. W.; Spencer, M. A.; Wang, Q. \& Dechow PC. A finite element analysis of masticatory stress hypotheses. Am. J. Phys. Anthropol., 145(1):1-10, 2011.

Dong-Xu, L.; Hong-Ning, W.; Chun-Ling, W.; Hong, L.; Ping, S. \& Xiao, Y. Modulus of elasticity of human periodontal ligament by optical measurement and numerical simulation. Angle Orthod., 81(2):229-36, 2011.

Freire, A. R.; Prado, F. B.; Rossi, A. C.; Noritomi, P. Y.; Neto, F. H. \& Caria, P. H. F. Biomechanics of the Human Canine Pillar Based on its Geometry Using Finite Element Analysis. Int. J. Morphol., 32(1):214-20, 2014.

Gomes de Oliveira, S.; Seraidarian, P. I.; Landre, J. Jr.; Oliveira, D. D. \& Cavalcanti, B. N. Tooth displacement due to occlusal contacts: a three-dimensional finite element study. J. Oral Rehabil., 33(12):874-80, 2006.

Hasegawa, A.; Shinya, A.; Nakasone, Y.; Lassila, L. V.; Vallittu, P. K.; \& Shinya, A. Development of 3D CAD/FEM Analysis System for Natural Teeth and Jaw Bone Constructed from XRay CT Images. Int. J. Biomater., 2010 pii: 659802, 2010.

Heckbert, P. S. \& Garland, M. Optimal triangulation and quadricbased surface simplification. Comput. Geom., 14(1-3):49-65, 1999.

Huang, J. Y.; Tsai, M. F.; Kao, P. F. \& Chen, Y. S. Automatic computer-aided sacroiliac joint index analysis for bone scintigraphy. Comput. Methods Programs Biomed., 98(1):1526, 2010.

Ichim, I.; Kieser, J. A. \& Swain, M. V. Functional significance of strain distribution in the human mandible under masticatory load: numerical predictions. Arch. Oral Biol., 52(5):465-73, 2007.

Is s,eri, H.; Tekkaya, A.E.; Oztan, O.; \& Bilgiç, S. Biomechanical effects of rapid maxillary expansion on the craniofacial skeleton, studied by the finite element method. Eur. J. Orthod., 20(4):347-56, 1998

Kelley, D. J.; Farhoud, M.; Meyerand, M. E.; Nelson, D. L.; Ramirez, L. F.; Dempsey, R. J.; Wolf, A. J.; Alexander, A. L. \& Davidson, R. J. Creating physical 3D stereolithograph models of brain and skull. PLOS ONE, 2(10):e1119, 2010.

Kondo, T. \& Wakabayashi, N. Influence of molar support loss on stress and strain in premolar periodontium: a patient-specific FEM study. J. Dent., 37(7):541-8, 2009.

Lovald, S. T.; Wagner, J. D. \& Baack, B. Biomechanical optimization of bone plates used in rigid fixation of mandibular fractures. J. Oral Maxillofac. Surg., 67(5):973-85, 2009.
Motoyoshi, M.; Ueno, S.; Okazaki, K. \& Shimizu, N. Bone stress for a mini-implant close to the roots of adjacent teeth--3D finite element analysis. Int. J. Oral Maxillofac. Surg., 38(4):363-8, 2009.

Nakajima, A.; Murata, M.; Tanaka, E.; Arai, Y.; Fukase, Y.; Nishi, Y.; Sameshima, G. \& Shimizu, N. Development of three-dimensional FE modeling system from the limited cone beam CT images for orthodontic tipping tooth movement. Dent. Mater. J., 26(6):882-91, 2007.

Ona, M. \& Wakabayashi, N. Influence of alveolar support on stress in periodontal structures. J. Dent. Res., 85(12):1087-91, 2006.

Panagiotopoulou, O. Finite element analysis (FEA): applying an engineering method to functional morphology in anthropology and human biology. Ann. Hum. Biol., 36(5):60923, 2009.

Panagiotopoulou, O.; Kupczik, K. \& Cobb, S. N. The mechanical function of the periodontal ligament in the macaque mandible: a validation and sensitivity study using finite element analysis. J. Anat., 218(1):75-86, 2001.

Pellizzer, E.; Verri, F.; Falcón-Antenucci, R. M.; Júnior, J. F.; de Carvalho, P. S.; de Moraes, S. L. \& Noritomi, P. Y. Stress analysis in platform-switching implants: a 3-dimensional finite element study. J. Oral Implantol., 38(5):587-94, 2012.

Pellizzer, E. P.; Verri, F. R.; de Moraes, S. L.; Falcón-Antenucci, R. M.; de Carvalho, P. S. \& Noritomi, P. Y. Influence of the implant diameter with different sizes of hexagon: analysis by 3-dimensional finite element method. J. Oral Implantol., 39(4):425-31, 2013.

Poiate, I. A.; Vasconcellos, A. B.; Andueza, A.; Pola, I. R. \& Poiate, E. Jr. Three dimensional finite element analyses of oral structures by computerized tomography. J. Biosci. Bioeng., 106(6):606-9, 2008.

Poiate, I. A.; Vasconcellos, A. B.; de Santana, R. B. \& Poiate, E. Three-dimensional stress distribution in the human periodontal ligament in masticatory, parafunctional, and trauma loads: finite element analysis. J. Periodontol., 80(11):1859-67, 2009.

Prado, F. B.; Noritomi, P. Y.; Freire, A. R.; Rossi, A. C.; Neto, F. H. \& Caria, P. H. F. Stress Distribution in Human Zygomatic Pillar Using Three-Dimensional Finite Element Analysis. Int. J. Morphol., 31(4):1386-92, 2013.

Provatidis, C. G.; Georgiopoulos, B.; Kotinas, A. \& McDonald, J. P. Evaluation of craniofacial effects during rapid maxillary expansion through combined in vivo/in vitro and finite element studies. Eur. J. Orthod., 30(5):437-48, 2008.

Rudolph, D. J.; Willes, P. M. G. \& Sameshima, G. T. A finite element model of apical force distribution from orthodontic tooth movement. Angle Orthod., 71(2):127-31, 2001. 
ROSSI, A. C.; FREIRE, A. R.; BOTACIN, P. R.; CARIA, P. H. F. \& PRADO, F. B. Computer graphics applied to Anatomy: a study of two Bio-CAD modeling methods on finite element analysis of human edentulous hemi-mandible. Int. J. Morphol., 32(3):803-811, 2014.

Saha, P. K.; Liang, G.; Elkins, J. M.; Coimbra, A.; Duong, L. T.; Williams, D. S. \& Sonka, M. A new osteophyte segmentation algorithm using partial shape model and its applications to rabbit femur anterior cruciate ligament transection via microCT imaging. IEEE Trans. Biomed. Eng., 58(8):2212-27, 2011.

Silva, D. N.; Gerhardt de Oliveira, M.; Meurer, E.; Meurer, M. I.; Lopes da Silva, J. V. \& Santa-Bárbara, A. Dimensional error in selective laser sintering and 3D-printing of models for craniomaxillary anatomy reconstruction. J. Craniomaxillofac. Surg., 36(8):443-9, 2008.

Strait, D. S.; Grosse, I. R.; Dechow, P. C.; Smith, A. L.; Wang, Q.; Weber, G. W.; Neubauer, S.; Slice, D. E.; Chalk, J.; Richmond, B. G.; Lucas, P. W.; Spencer, M. A.; Schrein, C.; Wright, B. W.; Byron, C. \& Ross, C. F. The structural rigidity of the cranium of Australopithecus africanus: implications for diet, dietary adaptations, and the allometry of feeding biomechanics. Anat. Rec. (Hoboken), 293(4):583-93, 2010.

Strait, D. S.; Weber, G. W.; Neubauer, S.; Chalk, J.; Richmond, B. G.; Lucas, P. W.; Spencer, M. A.; Schrein, C.; Dechow, P. C.; Ross, C. F.; Grosse, I. R.; Wright, B. W.; Constantino, P.; Wood, B. A.; Lawn, B.; Hylander, W. L.; Wang, Q.; Byron, C.; Slice, D. E. \& Smith, A. L. The feeding biomechanics and dietary ecology of Australopithecus africanus. Proc. Natl. Acad. Sci. USA, 106(7):2124-9, 2009.

Sun, W.; Starly, B.; Nam, J. \& Darling, A. Bio-CAD modeling and its applications in computer-aided tissue engineering. Comput. Aided Des., 37(11):1097-14, 2005.

Szúcs, A.; Bujtár, P.; Sándor, G. K. \& Barabás, J. Finite element analysis of the human mandible to assess the effect of removing an impacted third molar. J. Can. Dent. Assoc., 76:a72, 2010.

Takahashi, H.; Moriyama, S.; Furuta, H.; Matsunaga, H.; Sakamoto, Y. \& Kikuta, T. Three lateral osteotomy designs for bilateral sagittal split osteotomy: biomechanical evaluation with threedimensional finite element analysis. Head Face Med., 6:4, 2010.

Tanne, K.; Matsubara, S. \& Sakuda, M. Stress distributions in the maxillary complex from orthopedic headgear forces. Angle Orthod., 63(2):111-8, 1993.

von Ehler, E.; Trinks, R. D.; Schmitz, K. P. \& Pfau, H. Zur Berechnung von Verformungen der durch Punktlast beanspruchten menschlichen Schaedelkalotte unter Verwendung der Methode der Finiten Elemente. Wiss. Z. Rostock, 24:969-79, 1975.

Wang, Q.; Smith, A. L.; Strait, D. S.; Wright, B. W.; Richmond, B. G.; Grosse, I. R.; Byron, C. D. \& Zapata, U. The global impact of sutures assessed in a finite element model of a macaque cranium. Anat. Rec. (Hoboken), 293(9):1477-91, 2010.

\author{
Correspondence to: \\ Ana Cláudia Rossi \\ Department of Morphology \\ Piracicaba Dental School, P.O. Box 52 \\ University of Campinas - UNICAMP \\ 13414-903, Piracicaba, SP \\ BRAZIL
}

Email: anaanatomia@gmail.com

Received: 11-09-2013

Accepted: 28-04-2014 